\title{
CORRIGENDUM
}

\section{Impact of bivalirudin and genous stent in patients with acute myeloid leukemia undergoing emergency percutaneous coronary angioplasty for acute coronary syndrome}

G Galasso, T Niglio, S De Luca, C De Biase, V Parisi and F Piscione

Leukemia (2013) 27, 758; doi:10.1038/leu.2012.320

Correction to: Leukemia (2012) 26, 2300-2301; doi:10.1038/ leu.2012.93

Since the publication of this article, it has been brought to the authors' attention that there are two instances where the word 'bivalirudin' has been incorrectly spelt as 'bivaluridin' (once in the title, the other on page 2).

The authors would like to apologize for any inconvenience this may have caused. 